\title{
O DESAFIO EDUCACIONAL DOS BIBLIOTECÁRIOS NAS BIBLIOTECAS MULTINÍVEIS DA REDE FEDERAL DE EDUCAÇÃO PROFISSIONAL, CIENTÍFICA E TECNOLÓGICA
}

\author{
Miriã Santana Veiga \\ Bibliotecária Documentalista \\ Instituto Federal de Educação, Ciência e Tecnologia de Rondônia (IFRO) \\ miria.veiga@ifro.edu.br \\ Jussara Santos Pimenta \\ Doutora em Educação \\ Professora da Universidade Federal de Rondônia (UNIR) \\ jussara.pimenta@unir.br \\ Luciana Semeão da Silva \\ Mestranda em Educação - Universidade Federal de Rondônia (UNIR) \\ luciana.silva@ifro.edu.br
}

Resumo

\begin{abstract}
Este trabalho faz parte de pesquisa desenvolvida em nível de mestrado em Educação, tendo como lócus do estudo, as bibliotecas do Instituto Federal de Educação, Ciência e Tecnologia de Rondônia (IFRO), pertencente à Rede Federal de Educação Profissional, Científica e Tecnológica (RFEPCT). O objetivo foi conhecer e entender as práticas e os projetos educativos, ambos desenvolvidos pelos profissionais Bibliotecários do IFRO. O método utilizado foi o indutivo, tendo como tipo de pesquisa, a pesquisa-ação. Os instrumentais utilizados foram análise documental e a aplicação de questionários semiestruturados. Como resultado do estudo, descobrimos que as bibliotecas da Rede Federal (EPCT), é um novo tipo de biblioteca, e deve ser chamada de "Biblioteca Multinível", também se observou que um dos maiores desafios educacionais dos bibliotecários, é o planejamento e a execução de projetos educativos informacionais, que vise a Competência Crítica em Informação do educando. Portanto, realizamos um mapeamento das atividades e as relacionamos com a criação de um Programa Educativo de Letramento Informacional, que visa à melhoria e o planejamento das atividades e projetos educativos ofertados pelas Bibliotecas da do IFRO e da Rede Federal (EPCT).
\end{abstract}

Palavras-chave: Letramento informacional. Bibliotecário. Educação profissional.

\section{CONSIDERAÇÕES INICIAIS}

A pesquisa bibliográfica feita para este estudo primeiramente ressaltou a importância da informação como um dos direitos essenciais do homem, esse direito destaca-se no artigo dezenove da Declaração Universal dos Direitos Humanos (ONU, 1948, p.04), onde afirma que: "Todo ser humano tem direito à liberdade de opinião e expressão; este direito inclui a liberdade de, sem interferência, ter opiniões e de procurar, receber e transmitir informações e ideias por quaisquer meios e independentemente de fronteiras". Este artigo denota a realidade da chamada "Sociedade da Informação", no qual estamos inseridos.

A expressão "sociedade da informação" passou a ser utilizada, nos últimos anos desse século, como substituto para o conceito complexo de "sociedade pós-industrial" e como forma de transmitir o conteúdo específico do "novo paradigma técnicoeconômico". A realidade que os conceitos das 
ciências sociais procuram expressar refere-se às transformações técnicas, organizacionais e administrativas que têm como "fator-chave" não mais os insumos baratos de energia - como na sociedade industrial - mas os insumos baratos de informação propiciados pelos avanços tecnológicos na microeletrônica e telecomunicações. Esta sociedade pósindustrial ou "informacional", como prefere Castells, está ligada à expansão e reestruturação do capitalismo desde a década de 80 do século que termina. (WERTHEIN, 2000, p. 71).

No Brasil é assegurado a todos o acesso à informação, isso se encontra como direito individual e coletivo, na Constituição da República Federativa do Brasil de 1988. No país centenas de profissionais bibliotecários trabalham na Rede Federal de Educação Profissional, Científica e Tecnológica (RFEPCT) e estes têm o desafio e a responsabilidade de gerenciar e dispor informações, que deverão ser utilizadas para gerar conhecimento nas áreas de educação, ciência e tecnologia.

Com a criação da Rede Federal (EPCT), que foi instituída pela lei federal $\mathrm{n}^{\circ} 11.892$, de 29 de dezembro de 2008, os profissionais bibliotecários contratados, se deparam com um novo tipo de biblioteca que está sendo conhecida como Biblioteca Multinível. Almeida (2015, p.43) afirma que a Biblioteca Multinível: "[...] é percebida como uma organização que atende aos usuários de diversos níveis de ensino e modalidades educativas".

No Brasil existem oito tipos de bibliotecas, que são elas: A Biblioteca Nacional, que gerencia a memória do país; As Bibliotecas Públicas, responsáveis por gerenciar a memórias dos Estados da Federação e dos municípios; As Bibliotecas Universitárias, que dão apoio à pesquisa acadêmica nas Instituições de Ensino Superior (IES); As Bibliotecas Escolares, que devem incentiva o gosto pela leitura e a inserção do educando no mundo da informação; As Bibliotecas Especializadas, responsáveis por acervos e usuários que buscam conhecimentos específicos sobre um tema, como por exemplo, as bibliotecas especializadas na área da saúde Medicina e Enfermagem; As Bibliotecas Infantis que são destinadas a recreação com uso inicial da informação e por fim, as Bibliotecas Especiais, como por exemplo, as bibliotecas com conteúdos específicos em Braille e as bibliotecas prisionais. Porém, Almeida (2015), afirma que o país conta com um novo tipo de biblioteca que seriam as Bibliotecas Multiníveis, que são unidades de informação, que devem atender às necessidades de estudo, consulta e pesquisa de um público variado e com necessidades formativas e informativas diferenciadas, ele cita como exemplo, as bibliotecas das instituições da Rede Federal (EPCT) (Quadro $1)$.

Quadro - 1 Tipos de bibliotecas existentes no Brasil.

\begin{tabular}{|c|l|}
\hline $\begin{array}{c}\text { TIPO DE } \\
\text { BIBLIOTECA }\end{array}$ & \multicolumn{1}{c|}{ FINALIDADE } \\
\hline NACIONAL & $\begin{array}{l}\text { Preservar a memória nacional, quanto à produção bibliográfica e } \\
\text { documental de uma nação. }\end{array}$ \\
\hline PÚBLICA & $\begin{array}{l}\text { Atender às necessidades de estudo, consulta e recreação de } \\
\text { determinada comunidade, independente de classe social, cor, religião ou } \\
\text { profissão. Segundo a entidade mantenedora, estas podem ser federais, } \\
\text { estaduais ou municipais. }\end{array}$ \\
\hline UNIVERSITÁRIA & $\begin{array}{l}\text { Atender às necessidades de estudo, consulta e pesquisa de professores } \\
\text { e alunos universitários em nível superior de graduação e pós-graduação. } \\
\text { Segundo a organização das coleções, podem ser centralizadas ou } \\
\text { descentralizadas. }\end{array}$ \\
\hline ESCOLAR & $\begin{array}{l}\text { Fornecer material informacional necessário às atividades de } \\
\text { professores e alunos de uma escola. Deve estar intimamente relacionada } \\
\text { coma escola, para funcionar como verdadeiro complemento das atividades } \\
\text { realizadas em sala de aula, dando suporte informacional necessário aos } \\
\text { processos de ensino-aprendizagem. Desempenha importante papel na } \\
\text { formação de leitores e no fomento à prática da leitura. }\end{array}$ \\
\hline
\end{tabular}




\begin{tabular}{|c|c|}
\hline ESPECIALIZADA & $\begin{array}{l}\text { Atende a um grupo restrito de usuários, reunindo e divulgando } \\
\text { documentos de um campo específico do conhecimento. Podem ser } \\
\text { subordinadas a uma entidade científica e de pesquisa, a uma empresa } \\
\text { industrial ou comercial, ou mesmo a um serviço público especializado. }\end{array}$ \\
\hline INFANTIL & $\begin{array}{l}\text { Destinadas à recreação para crianças, incluindo estímulo à leitura, com } \\
\text { acervo bem selecionado para tal propósito. Pode proporcionar atividades } \\
\text { como clube da leitura, escolinhas de arte, exposições, dramatizações, hora } \\
\text { do conto, contação de histórias, entre outras. }\end{array}$ \\
\hline ESPECIAL & $\begin{array}{l}\text { Atender a uma categoria especial de usuários, tais como: pessoas com } \\
\text { dificuldades de visão e deficientes visuais. Deve fornecer, neste caso, } \\
\text { acervo sonoro ou em suporte papel com Braille, ou com escrita em tipos } \\
\text { maiores. }\end{array}$ \\
\hline MULTINÍVEL & $\begin{array}{l}\text { Atender às necessidades de estudo, consulta e pesquisa de Professores, } \\
\text { servidores técnico-administrativos e alunos em nível profissionalizante, } \\
\text { médio, técnico, superior de graduação e pós-graduação (lato e stricto } \\
\text { sensu). Segundo a organização das coleções, assemelham-se às } \\
\text { universitárias, podendo ser centralizadas ou descentralizadas. São, por } \\
\text { exemplo, as bibliotecas das instituições da Rede Federal de Educação } \\
\text { Profissional, Científica e Tecnológica no Brasil. }\end{array}$ \\
\hline
\end{tabular}

Fonte: Almeida (2015, p. 44-45)

Assim sendo, as Bibliotecas Multiníveis da Rede Federal (EPCT) não devem ser consideradas apenas bibliotecas escolares, haja vista, que além de atender os alunos do ensino médio integrado com idades que variam dos 14 aos 19 anos, estas também, atendem os alunos das graduações e de pós-graduações, tanto nas modalidades latu senso e strictu sensu oferecidos pela rede. As bibliotecas multiníveis da Rede Federal (EPCT), também atendem os alunos dos cursos das modalidades subsequentes, que fazem apenas os cursos técnicos. Os educandos dessas modalidades, em sua maioria são adultos, cuja idade varia dos 30 aos 75 anos de idade, esses alunos já possuem o ensino médio e muitos já estão inseridos no mercado de trabalho e procuram apenas se capacitar. Assim sendo, além de atender um universo distinto de modalidades de cursos e usuários, as bibliotecas multiníveis têm outra característica que as singularizam como uma nova tipologia de unidades de informação. Isso ocorre, em vista do seu planejamento de atividades educativas, que mais uma vez, são afetas pelas características de seus usuários (idade, nível formativo, necessidade de informação, alfabetização digital e etc.), que afetam os projetos e planejamento educativos informacionais. De acordo com Hubner Apud Bernet (2017) "Aqueles que planejam e organizam uma biblioteca, devem pensar mais como educadores e menos como prestadores de serviço". Desse modo, um dos maiores desafios educacionais do profissional bibliotecário na Rede Federal (EPCT) é buscar o planejamento de atividades e serviços educativos ofertados pelas bibliotecas, que vise à formação de alunos competentes no uso da informação. Porém, como enfrentar esse desafio em uma biblioteca multinível?

Em vista deste questionamento, nos aprofundamos no conceito de Information Literacy, que é uma área teórica da Ciência da Informação, onde os "focos" de pesquisa são bem recentes no Brasil. Porém, está área desperta interesse e tem importância, haja vista, que ela objetiva discutir e melhorar a aprendizagem do educando nas bibliotecas, incentivando no mesmo, o hábito do "aprender a aprender" com o uso correto da informação.

O caminho da humanização e da sustentabilidade exige que os agentes de aprendizagem sejam capazes de transformar as formas de gestão social do conhecimento para colocá-las à disposição de todos, sem exclusões. Isso implica a necessidade das pessoas aprenderem a buscar e usar a informação para transformá-la em conhecimento em prol da vida. Não há conhecimento sem considerar as experiências pessoais e as informações. Nesses termos, a infraestrutura de informação da sociedade possui papel crucial em seu desenvolvimento. Inclui, pois, acesso à internet, aos museus, arquivos, centros de documentação e às bibliotecas (GASQUE, 2012, p. 151, grifo nosso). 
O bibliotecário é um agente educacional, que contribui para o processo de aprendizagem e a criação de conhecimento, pois este gerencia informações, nos seus mais variados suportes. Pois, o acesso à informação tornou-se para o homem, inserido na Sociedade da Informação, um dos pilares para a sua formação educativa e sua relação com o mundo e com os outros. Paulo Freire (1996, p. 24), afirmou que:

A consciência do mundo e a consciência de si como ser inacabado necessariamente inscrevem o ser consciente de sua inconclusão num permanente movimento de busca. Na verdade, seria uma contradição se, inacabado e consciente do inacabamento. $\mathrm{O}$ ser humano não se inserisse em tal movimento. É neste sentido que, para mulheres e homens, estar no mundo necessariamente significa estar com o mundo e com os outros. Estar no mundo sem fazer história, sem por ela ser feito, sem fazer cultura, sem "tratar" sua própria presença no mundo, sem sonhar, sem cantar, sem musicar, sem pintar, sem cuidar da terra, das águas, sem usar as mãos, sem esculpir, sem filosofar, sem pontos de vista sobre o mundo, sem fazer ciência, ou teologia, sem assombro em face do mistério, sem aprender, sem ensinar, sem ideias de formação, sem politizar não é possível (FREIRE, 1996, p. 24, grifo nosso).

Portanto, o profissional bibliotecário tem o dever de ajudar a educar e formar cidadãos éticos e competentes no uso da informação nas suas comunidades de aprendizagem. Os dados deste estudo apontam para a necessidade de programas educacionais planejados, voltados para o uso competente da informação em bibliotecas, principalmente bibliotecas escolares e universitárias. Pois, primariamente, a informação é essencial para os processos cognitivos dos educandos, de acordo com Messias (2005, p.97) "a informação se constitui uma prática social, envolvendo um sujeito cognitivo que atribui e comunica sentidos, gerando conhecimento para si e seu grupo social". Portanto, existe a necessidade de se pensar uma formação educativa para o uso da informação em bibliotecas, isso ocorre, porque os educandos demonstram dificuldades crescentes em buscar e usar a informação, o que vem a ser um paradoxo intrigante na sociedade contemporânea, que está sendo chamada de "Sociedade da Informação" (ALMEIDA, 2015).

\section{O LETRAMENTO INFORMACIONAL E AS BIBLIOTECAS MULTINÍVEIS DO INSTITUTO FEDERAL DE EDUCAÇÃO CIÊNCIA E TECNOLOGIA DE RONDÔNIA (IFRO).}

Como já explicitado, as bibliotecas multiníveis são bibliotecas que atendem a necessidades informacionais de diversos públicos em diversas escalas formativas, são Professores, servidores técnicoadministrativos e alunos em nível profissionalizante, médio, técnico, superior de graduação e pós-graduação (lato e stricto sensu). Essas são as principais características das bibliotecas da rede Federal (EPCT) e seus acervos assemelham-se às universitárias, podendo ser centralizadas ou descentralizadas. Buscando entender o desafio educacional dos bibliotecários da Rede Federal (EPCT) em educar informacionalmente os usuários das bibliotecas multiníveis, nos propormos entender o papel educativo do bibliotecário na bibliotecas.

Para isso, como já informado, buscamos dentro da Ciência da Informação os conceitos de Information Literacy. O termo foi criado e destacado no relatório intitulado The information service environment relationships and priorities $^{l}$ (1974) pelo bibliotecário norte americano Paul G. Zurkowski. O autor defendia que, em vista da grande disponibilidade de informações, os cidadãos americanos deveriam receber uma formação voltada para o uso competente da informação. O documento propôs a adoção, nos Estados Unidos, de práticas de Letramento Informacional, na formação de alunos e trabalhadores americanos.

O Information Literacy, de acordo com Veiga (2017, p.08):

[...] é a capacidade de identificar, acessar, localizar, obter, usar eticamente a informação e avaliar todo o processo em prol de uma contínua aprendizagem. O letramento informacional possui componentes que são necessários para a sua real efetivação, esses componentes são: 1$\mathrm{O}$ processo investigativo; $2-\mathrm{O}$ aprendizado ativo; 3- $\mathrm{O}$ aprendizado independente; 4- $\mathrm{O}$ pensamento crítico; 5- O aprender a aprender;

\footnotetext{
1 “As relações e as prioridades do ambiente de serviço de informação" Tradução das autoras.
} 
6- O aprendizado ao longo da vida. Todos esses componentes, são necessários para que leve o educando ao aprendizado, não apenas ao longo da vida, mas também que, o auxilie no pensar reflexivo com o uso correto da informação.

O Information Literacy chegou ao Brasil a partir do ano 2000 e ganhou destaque com estudos das bibliotecárias Doutoras Dudziak (2003); Campello (2009) e Gasque (2012). Porém, a área ganhou um destaque especial nos estudos da professora e pesquisadora da Universidade Federal de Minas (UFMG) Bernadete Campello, que trabalhou com a difusão do Information Literacy com o Grupo de Estudos em Bibliotecas Escolares (GEBE) e trouxe para o país Carol Kuhlthau a maior referência sobre information literacy no mundo. O grupo traduziu diversas obras da autora, essas obras tratam sobre o papel educacional das bibliotecas escolares e letramento informacional.

No entanto, na pesquisa bibliográfica realizada para este estudo, percebemos que há um grande entrave para a difusão do Information literacy no país, pois o termo recebeu diversas traduções como, por exemplo: Letramento Informacional; Alfabetização Informacional; Competência Informacional e Habilidade Informacional. Porém, corrobora-se com Gasque (2012), quando a mesma afirma que todos os conceitos exemplificados acima, fazem parte do mesmo processo educativo, que a autora propôs e denominou de Letramento Informacional.

De acordo com Gasque (2012), O letramento Informacional, busca alfabetizar o educando com competências e habilidades para usar corretamente a informação e isso pode ocorrer em etapas que fazem parte do mesmo ciclo de aprendizagem do educando, que utilizará essa competência por toda sua vida (Quadro 2).

Quadro - 2 Etapas do Letramento Informacional

\section{LETRAMENTO INFORMACIONAL}

É um Processo de aprendizagem voltado para o desenvolvimento de competências para buscar e usar a informação na resolução de problemas ou tomada de decisões. O Letramento Informacional é um processo investigativo, que propicia o aprendizado ativo, independente e contextualizado; o pensamento reflexivo e o aprender a aprender ao longo da vida. Pessoas letradas têm capacidade de tomar melhores decisões por saberem selecionar e avaliar as informações e transformá-las em conhecimento aplicável.

t

\section{ALFABETIZAÇÃO INFORMACIONAL}

Refere-se à primeira etapa do Letramento Informacional, isto é, abrange os contatos iniciais com as ferramentas, produtos e serviços informacionais. Nessa etapa, o indivíduo desenvolve noções, por exemplo, sobre a organização de dicionários e enciclopédias, de como as obras são produzidas, da organização da biblioteca e dos significados do número de chamada, classificação, índice, sumário, autoria, bem como o domínio das funções básicas do computador - uso do teclado, habilidade motora para usar o mouse, dentre outros. O ideal é que a alfabetização informacional se inicie na educação infantil.

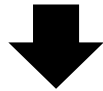

\section{COMPETÊNCIA INFORMACIONAL}

Refere-se à capacidade do aprendiz de mobilizar o próprio conhecimento que o ajuda a agir em determinada situação. Ao longo do processo de Letramento Informacional, os aprendizes desenvolvem competências para identificar a necessidade de informação, avaliá-la, buscá-la e usá-la eficaz e eficientemente, considerando os aspectos éticos, legais e econômicos. 


\section{HABILIDADE INFORMACIONAL}

Realização de cada ação específica e necessária para alcançar determinada competência. Para o aprendiz ser competente em identificar as próprias necessidades de informação, por exemplo, é necessário desenvolver habilidades de formular questões sobre o que deseja pesquisar, explorar fontes gerais de informação para ampliar o conhecimento sobre o assunto, delimitar o foco, identificar palavraschave que descrevem a necessidade de informação, dentre outras.

Fonte: Veiga, (2017, p. 40-41).

Assim sendo, concordamos com Gasque (2012) de que o Termo Information literacy deveria se "traduzido" ou compreendido como "Letramento Informacional" no Brasil, haja vista, que a educação para a informação, começa na alfabetização inicial da criança e se torna um letramento necessário para os educandos e cidadãos não marginalizados da sociedade da informação.

\section{METODOLOGIA DO ESTUDO}

O lócus do estudo desta pesquisa foi o IFRO e as suas bibliotecas. O IFRO possui atualmente nove Campi, e todos estes possuem unidades de informação. Em nosso levantamento documental, foram encontrados: 14 bibliotecários, um assistente administrativo e 20 auxiliares de Biblioteca. Todos estes profissionais foram contratados através de concursos e atuam diretamente nas bibliotecas do instituto, excetuando-se a assessoria de biblioteca que fica na reitoria na cidade de Porto Velho, capital do Estado de Rondônia e são responsáveis por coordena às ações destinadas às Bibliotecas da IFRO. De acordo com o Regimento geral do IFRO, Art. 103. Compete ao Assessor de Bibliotecas:

I. Planejar, coordenar e acompanhar as atividades de informação relacionadas ao acervo das Bibliotecas do IFRO;

II. Propor normas e regulamentações para publicações. Consultas, empréstimos e formação do acervo bibliográfico, em consonância com as legislações atuais e com as orientações provenientes do Ministério da Educação e Secretaria de Educação Profissional e Tecnológica;

III. Orientar as bibliotecas dos Campi para execução dos serviços prestados à comunidade; $\mathrm{e}$

IV. Gerenciar o Sistema de Gestão de Biblioteca, em parceria com a DGTI, de forma a garantir o pleno funcionamento de suas atividades e a utilização adequada do sistema, bem como a unificação das ações administrativas nas Coordenações de Bibliotecas do IFRO, visando assim à celeridade e eficiência dos trabalhos.
Nesse preâmbulo a rede de bibliotecas do IFRO tem como objetivo:

Art. $2^{\circ}(\ldots)$ reunir, organizar, divulgar, manter atualizado, preservado e em permanentes condições de uso todo o acervo existente e o que venha a ser incorporado ao patrimônio por aquisição, permuta ou doação.

Art. $3^{\circ}$ As bibliotecas do IFRO estão vinculadas à Direção de Ensino e são tecnicamente responsáveis pelo provimento das informações necessárias às atividades de ensino, pesquisa e extensão da Instituição (REGULAMENTO, 2015, p. 5).

Para este estudo primeiramente, realizamos a revisão bibliográfica sobre o tema, isso nos possibilitou construir nosso referencial teórico, principalmente, no tocante aos conceitos de educação, de letramento e letramento informacional. $\mathrm{O}$ método utilizado foi o indutivo, tendo como tipo de pesquisa, a pesquisa-ação, que é uma proposta metodológica que têm por objetivo superar a visão do pesquisador de ser apenas o observador de um problema, ele deve buscar contribuir na mudança de uma dada realidade, buscando a aprendizagem para todos os sujeitos da pesquisa (PIMENTA, 2005).

Os instrumentais utilizados foram análise documental, que nos ajudou a realizar um mapeamento das atividades e projetos educativos realizados pelas bibliotecárias e por fim, a aplicação de questionários semiestruturados as bibliotecárias, onde buscamos compreender a visão e as experiências das profissionais participantes do estudo. O questionário foi simples, contendo apenas 04 questões, com os dados coletados foi possível à estruturação de um Programa Educativo de Letramento Informacional para o IFRO e a Rede Federal (EPCT).

$\mathrm{Na}$ pesquisa documental, também conseguimos localizar dois relatórios organizados pela a Assessoria de Bibliotecas (ABIB) do IFRO. Estes relatórios foram: o primeiro Relatório Geral das Atividades Assessoria de Biblioteca e Coordenação de Biblioteca do IFRO, referente ao ano de 2015, publicado em fevereiro de 2016 e o segundo 
Relatório Geral de Atividades da Assessoria e Coordenação de Biblioteca, publicado no ano de 2018. Localizamos também, os documentos norteadores das bibliotecas da instituição que são: o Manual de serviços das Bibliotecas do Instituto Federal, publicado no ano de 2011, a Resolução $n^{\circ}$ 21/CONSUP/IFRO, que discorre sobre o Regulamento de Funcionamento das Bibliotecas do Instituto e por fim, a Resolução $n^{\circ}$ 22/CONSUP/IFRO, que dispõe sobre a Política de Desenvolvimento de Coleções, ambos foram publicados em julho de 2015. Porém, o foco de nossos estudos foram os projetos e trabalhos educativos desenvolvidos pelas bibliotecárias do IFRO, onde focamos nossa coleta de dados, nos relatórios da Assessoria de bibliotecas, que foram publicados nos anos de 2016 e 2018.

Com os dados coletados foi possível a estruturação das atividades e trabalhos educativos de um Programa Educativo de Letramento Informacional. Para a construção do programa, buscamos os conceitos e as práticas de Letramento informacional e Competência Informacional. Almeida (2015), afirma que o sucesso das bibliotecas depende da maestria em utilizar a informação e o conhecimento de sua equipe de profissionais (Bibliotecários e auxiliares de Biblioteca) para entender, atender e resolver as necessidades informacionais de sua comunidade acadêmica. Entendemos que a informação é, nos dias atuais, elemento fundamental para o sucesso pessoal e acadêmico do educando. Assim como Bufrem (1985), entendemos que a informação convertida em conhecimento é de substancial importância para o desenvolvimento de uma sociedade mais justa e igualitária.

\section{RESULTADOS}

Após a análise de documentos norteadores das bibliotecas e os seus relatórios anuais de atividades, identificamos que todas as bibliotecárias, executam atividades de cunho cultural, educacional e tecnológico nas bibliotecas. No total verificamos 43 atividades, o qual a dividimos em três grandes áreas (Quadro 3).

1 - Atividades culturais de leitura: Essas são atividades ligadas ao incentivo da leitura realizadas pelas bibliotecárias e auxiliares, foram localizadas 22 atividades;

2 - Atividades técnicas e de educação de usuários: Esses são trabalhos e cursos voltados para a apresentação das bibliotecas, das normas da instituição (regulamento e plano de desenvolvimento de coleções) e visitas guiadas, encontramos 15 atividades;

\section{3 - Atividades de Letramento} Informacional: Aqui foram encontradas atividades voltadas, especificamente para a formação dos alunos e professores para o uso competente da informação, como por exemplo, a capacitação voltada para o acesso à base de dados do Portal de Periódicos da Coordenação de Aperfeiçoamento de Pessoal de Nível Superior (CAPES) e a formatação de trabalhos acadêmicos. Identificamos apenas seis atividades (Quadro 3)

$\mathrm{Na}$ tabulação das atividades e dos dados, percebemos que algumas bibliotecas do IFRO, seguem o padrão esperado das bibliotecas "tecnicistas", isto é, bibliotecas que focam seus trabalhos quase que exclusivamente para a as atividades da técnica biblioteconômica (catalogação, classificação, alimentação de bases catalográficas, e outros...) e a realização da gestão administrativa como, por exemplo, os serviços de circulação de informação nos seus mais variados suportes (livros, revistas, DVD, e outros...). No entanto concordamos com Leal (2017, p.1) apud Brayner, quando afirma que devemos: "[...] pôr sob permanente suspeita a independência da técnica frente à teoria social. Em outras palavras, mais do que sistemas de classificação, a Biblioteconomia é uma atividade social e como tal, deve ser pensada em sua relação com a sociedade, à cultura e o poder". Portanto, as Bibliotecas, principalmente as bibliotecas escolares e universitárias, deverão ser espaços privilegiados e democráticos para o acesso a informação.

Campello (2009, p. 19), destaca que:

\begin{abstract}
Democratizar o acesso à informação, capacitar as pessoas para o uso crítico da informação, proporcionar condições que permitam a reflexão, a crítica e a construção de ideias por meio da leitura são ações constantemente recomendadas para $\mathrm{o}$ bibliotecário e, no bojo dessas ações, a biblioteca escolar é vista como espaço privilegiado para seu desenvolvimento. (CAMPELLO, 2009, p. 19)
\end{abstract}

$\mathrm{Na}$ pesquisa percebemos que no ano de 2015 a biblioteca do campus IFRO Vilhena, não executou nenhum projeto voltado para a área de educação de usuários ou de incentivo a 
leitura. Porém no ano de 2017 a biblioteca participou do projeto Ler Todo Dia, onde são realizadas atividades de incentivo a leitura na biblioteca (Quadro 3).

Quadro - 3 Atividades realizadas pelas bibliotecas do IFRO, referente aos anos de 2015 e 2017.

\begin{tabular}{|c|c|c|c|c|}
\hline CAMPUS & ANO & $\begin{array}{l}\text { ATIVIDADES CULTURAIS } \\
\text { DE LEITURA }\end{array}$ & $\begin{array}{l}\text { ATIVIDADE } \\
\text { TÉCNICA/ } \\
\text { EDUCAÇÃO DE } \\
\text { USUÁRIOS }\end{array}$ & $\begin{array}{l}\text { ATIVIDADE DE } \\
\text { LETRAMENTO } \\
\text { INFORMACIONAL }\end{array}$ \\
\hline \multirow[t]{2}{*}{$\begin{array}{l}\text { CAMPUS } \\
\text { ARIQUEMES }\end{array}$} & 2015 & $\begin{array}{l}\text { Projeto de Extensão PRIMEIRA } \\
\text { SEMANA DA BIBLIOTECA E DO } \\
\text { LIVRO DO IFRO - CAMPUS } \\
\text { ARIQUEMES; } \\
\text { PROJETO DE EXTENSÃO } \\
\text { DIGITALIZAÇÃO DE MATERIAL } \\
\text { DE CONTEÚDO EDUCACIONAL } \\
\text { EM FITAS VHS (Desenvolvido pelo } \\
\text { professor Adilson); } \\
\text { CAMPANHAS: ADOTE UM } \\
\text { LIVRO DIDÁTICO direcionado } \\
\text { para servidores e discentes do IFRO - } \\
\text { Campus Ariquemes Adote um Livro } \\
\text { Didático (Biblioteca IFRO X } \\
\text { Biblioteca UNIR); } \\
\text { DECORAÇÃO JUNINA DA } \\
\text { BIBLIOTECA. }\end{array}$ & 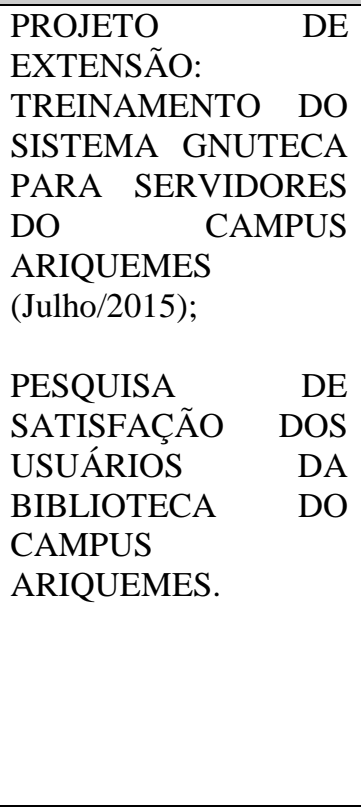 & $\begin{array}{lr}\text { PROJETO } & \text { DE } \\
\text { EXTENSÃO: } & \\
\text { ORIENTAÇÃ̃ } & \\
\text { SOBRE NORMAS DA } \\
\text { ABNT r PARA } \\
\text { FORMATAÇÃO } & \text { DE } \\
\text { TCC'S; } & \\
& \\
\text { ELABORAÇÃO } & \text { E } \\
\text { FORMATAÇÃO } & \text { DE } \\
\text { TRABALHOS } & \text { E } \\
\text { FORMATAÇÃO } & \text { DE } \\
\text { TRABALHOS } & \\
\text { ACADÊMICOS na III } \\
\text { Semana de Biologia do } \\
\text { Campus Ariquemes. }\end{array}$ \\
\hline & 2017 & $\begin{array}{l}\text { CAMPANHA \#DIA DE LER TODO } \\
\text { DIA; } \\
\text { MERGULHANDO NAS } \\
\text { PALAVRAS - - PROJETO DE } \\
\text { EXTENSÃO, em parceria com } \\
\text { docentes, discente e Taes da } \\
\text { biblioteca; } \\
\text { PROJETO LER PRA VALER }\end{array}$ & $\begin{array}{l}\text { Não foram localizadas } \\
\text { atividades nessa área }\end{array}$ & $\begin{array}{l}\text { Não foram localizadas } \\
\text { atividades nessa área }\end{array}$ \\
\hline $\begin{array}{l}\text { CAMPUS } \\
\text { CACOAL }\end{array}$ & 2015 & $\begin{array}{l}\text { SEMANA DO AMOR E DA } \\
\text { AMIZADE - realizado no período de } \\
8 \text { a } 12 \text { de junho de } 2015 \text { com carga } \\
\text { horária total de } 75 \text { h; } \\
\text { SEMANA NACIONAL DO LIVRO } \\
\text { E DA BIBLIOTECA - realizado no } \\
\text { período de } 04 \text { a } 05 \text { de novembro de } \\
\text { 2015, carga horária de } 30 \text { horas; } \\
\text { AMIGO DA BIBLIOTECA - } \\
\text { realizado no mês de dezembro de } \\
\text { 2015; } \\
\text { CAMPANHA DE DOAÇÃO DE } \\
\text { LIVROS - realizado no período de } \\
\text { maio a julho de } 2015, \text { que arrecadou } \\
\text { mais de } 450 \text { livros literários e } \\
\text { científicos para compor o acervo. }\end{array}$ & $\begin{array}{l}\text { Não foram localizadas } \\
\text { atividades nessa área }\end{array}$ & $\begin{array}{l}\text { Não foram localizadas } \\
\text { atividades nessa área }\end{array}$ \\
\hline
\end{tabular}




\begin{tabular}{|c|c|c|c|c|}
\hline & 2017 & $\begin{array}{l}\text { FEIRA DE TROCA DE LIVROS } \\
\text { FEIRA DE TROCA DE LIVROS } \\
\text { EM PARCERIA COM A UNIR- } \\
\text { Campus Cacoal. } \\
\text { SEMANA DO LIVRO E DA } \\
\text { BIBLIOTECA } \\
\text { (Realizado dentro das atividades do } \\
\text { Festival de Arte e Cultura da UNIR) } \\
\text { PROJETO AMIGO DA } \\
\text { BIBLIOTECA }\end{array}$ & $\begin{array}{l}\text { Não foram localizadas } \\
\text { atividades nessa área }\end{array}$ & $\begin{array}{l}\text { Não foram localizadas } \\
\text { atividades nessa área }\end{array}$ \\
\hline \multirow[t]{2}{*}{$\begin{array}{l}\text { CAMPUS } \\
\text { COLORADO } \\
\text { DO OESTE }\end{array}$} & 2015 & $\begin{array}{l}\text { CAMPANHA DE DOAÇÃO DOS } \\
\text { LIVROS DIDÁTICOS VENCIDOS } \\
\text { que estão acumulados de vários anos. }\end{array}$ & $\begin{array}{l}\text { PROJETO EM } \\
\text { PARCERIA COM O } \\
\text { PROFESSOR DE } \\
\text { MATEMÁTICA } \\
\text { Marcos Pinheiro Matos } \\
\text { do Campus, onde os } \\
\text { alunos coletaram dados } \\
\text { e informações sobre o } \\
\text { funcionamento da } \\
\text { biblioteca e os serviços } \\
\text { feitos. Os dados } \\
\text { estatísticos foram } \\
\text { tabulados para verificar } \\
\text { o quantitativo de } \\
\text { empréstimos domiciliar } \\
\text { e local dos livros } \\
\text { durante um determinado } \\
\text { período. Divididos em } \\
\text { diários mensais e } \\
\text { período. }\end{array}$ & $\begin{array}{l}\text { Não foram localizadas } \\
\text { atividades nessa área }\end{array}$ \\
\hline & 2017 & $\begin{array}{l}\text { CAMPANHA DIA DE LER TODO } \\
\text { DIA }\end{array}$ & $\begin{array}{l}\text { Não foram localizadas } \\
\text { atividades nessa área }\end{array}$ & $\begin{array}{l}\text { Não foram localizadas } \\
\text { atividades nessa área }\end{array}$ \\
\hline \multirow{3}{*}{$\begin{array}{l}\text { CAMPUS } \\
\text { GUAJARÁ- } \\
\text { MIRIM }\end{array}$} & 2015 & $\begin{array}{l}\text { Foi realizado juntamente com os } \\
\text { alunos um PROJETO DE DOAÇÃO } \\
\text { DE LIVROS - "DOE UMA } \\
\text { HISTÓRIA". }\end{array}$ & $\begin{array}{l}\text { Não foram localizadas } \\
\text { atividades nessa área }\end{array}$ & $\begin{array}{l}\text { Não foram localizadas } \\
\text { atividades nessa área }\end{array}$ \\
\hline & 2017 & DIA DE LER TODO DIA & $\begin{array}{l}\text { Não foram localizadas } \\
\text { atividades nessa área }\end{array}$ & $\begin{array}{l}\text { Não foram localizadas } \\
\text { atividades nessa área }\end{array}$ \\
\hline & 2015 & $\begin{array}{l}\text { PROJETO DE EXTENSÃO } \\
\text { LEITURA CIDADÃ APROVADO } \\
\text { pelo edital nº } 29 \text { da PROEX em } \\
\text { parceria com a biblioteca da UNIR e } \\
\text { Campus Cacoal, de julho a dezembro } \\
\text { de } 2015 \text {. Parceria com a biblioteca da } \\
\text { UNIR. }\end{array}$ & $\begin{array}{l}\text { A biblioteca } \\
\text { PARTICIPOU DA } \\
\text { REUNIÃO } \\
\text { PEDAGÓGICA DO } \\
\text { CAMPUS EM } \\
\text { FEVEREIRO } \\
\text { EXPONDO O } \\
\text { SISTEMA GNUTECA. }\end{array}$ & $\begin{array}{l}\text { PROJETO DE } \\
\text { DIVULGAÇÃO E } \\
\text { TREINAMENTO DO } \\
\text { PORTAL DE } \\
\text { PERIÓDICOS DA } \\
\text { CAPES aprovado pelo } \\
\text { edital 01 DEPEX - } \\
\text { Campus Ji-Paraná, em } \\
\text { andamento. }\end{array}$ \\
\hline
\end{tabular}


Relatos de Pesquisa

\begin{tabular}{|c|c|c|c|c|}
\hline \multirow[t]{2}{*}{$\begin{array}{l}\text { CAMPUS JI- } \\
\text { PARANÁ }\end{array}$} & & & & $\begin{array}{l}\text { Participação nas } \\
\text { atividades de } \\
\text { RECEPÇÃO DOS } \\
\text { ALUNOS, expondo o } \\
\text { funcionamento da } \\
\text { biblioteca e do sistema } \\
\text { Gnuteca. }\end{array}$ \\
\hline & 2017 & $\begin{array}{l}\text { Não foram localizadas atividades } \\
\text { nessa área }\end{array}$ & $\begin{array}{l}\text { "BEM-VINDOS A } \\
\text { 2017: SEJA PARTE } \\
\text { DO MUNDO IFRO" } \\
\\
\text { ACESSIBILIDADE E } \\
\text { INCLUSÃO NA } \\
\text { BIBLIOTECA do IFRO } \\
\text { Campus Ji-Paraná }\end{array}$ & $\begin{array}{l}\text { Não foram localizadas } \\
\text { atividades nessa área }\end{array}$ \\
\hline \multirow[t]{2}{*}{$\begin{array}{l}\text { CAMPUS } \\
\text { PORTO } \\
\text { VELHO- } \\
\text { CALAMA }\end{array}$} & 2015 & $\begin{array}{l}2^{\text {a }} \text { CAMPANHA DE } \\
\text { ARRECADAÇÃO DE LIVROS DE } \\
\text { LITERATURA E AUTOAJUDA; } \\
\text { CAMPANHA DO PERDÃO para } \\
\text { recuperação das obras emprestadas e } \\
\text { que estavam atrasadas devido ao } \\
\text { período de greve; } \\
\text { Execução do Projeto “MOSTRA } \\
\text { FOTOGRÁFICA: 100 ANOS DE } \\
\text { HISTÓRIA: ONTEM E HOJE”; } \\
\text { Atividades de extensão: SEMANA } \\
\text { DA CONSCIÊNCIA NEGRA, } \\
\text { I SEMINÁRIO DE EDUCAÇÃO } \\
\text { INCLUSIVA E DIVERSIDADE E } \\
\text { II FEIRA HISPÂNICA DO } \\
\text { CAMPUS CALAMA. }\end{array}$ & $\begin{array}{l}\text { IMPLANTAÇÃO DO } \\
\text { SISTEMA } \\
\text { ANTIFURTO em } \\
\text { março de 2015; } \\
\text { USO DO MÓDULO } \\
\text { "CIRCULAÇÃO DE } \\
\text { MATERIAL" no } \\
\text { sistema Gnuteca, ou } \\
\text { seja, todo o setor de } \\
\text { circulação de material } \\
\text { passou a ser } \\
\text { informatizado em abril } \\
\text { de } 2015 \text {. }\end{array}$ & $\begin{array}{l}\text { TREINAMENTO DE } \\
\text { USUÁRIOS PARA } \\
\text { USO DA } \\
\text { BIBLIOTECA E DO } \\
\text { SISTEMA } \\
\text { GNUTECA. }\end{array}$ \\
\hline & 2017 & LEITOR DO MÊS DE OUTUBRO & $\begin{array}{l}\text { EXPOSIÇÃO DE } \\
\text { PINTURA - } \\
\text { PAISAGENS DO } \\
\text { MUNDO }\end{array}$ & $\begin{array}{l}\text { TREINAMENTO } \\
\text { PARA O USO DO } \\
\text { PORTAL DE } \\
\text { PERIÓDICOS DA } \\
\text { CAPES. }\end{array}$ \\
\hline $\begin{array}{c}\text { CAMPUS } \\
\text { PORTO VELHO } \\
\text { ZONA NORTE }\end{array}$ & 2015 & $\begin{array}{l}2^{a} \text { CAMPANHA DE } \\
\text { ARRECADAÇÃO DE LIVROS DE } \\
\text { LITERATURA E AUTOAJUDA; } \\
1^{\text {a } C A M P A N H A ~ D O ~ P E R D A ̃ O . ~} \\
\text { Recuperação das obras que não } \\
\text { foram devolvidas no tempo certo. } \\
\\
\text { PROJETO CONTANDO E } \\
\text { ENCANTANDO - Apresentações } \\
\text { peças teatrais com fantoches, e } \\
\text { Leituras de historinhas, para alunos }\end{array}$ & $\begin{array}{l}\text { Não foram } \\
\text { localizadas atividades } \\
\text { nessa área }\end{array}$ & $\begin{array}{c}\text { Não foram localizadas } \\
\text { atividades nessa área }\end{array}$ \\
\hline
\end{tabular}


Relatos de Pesquisa

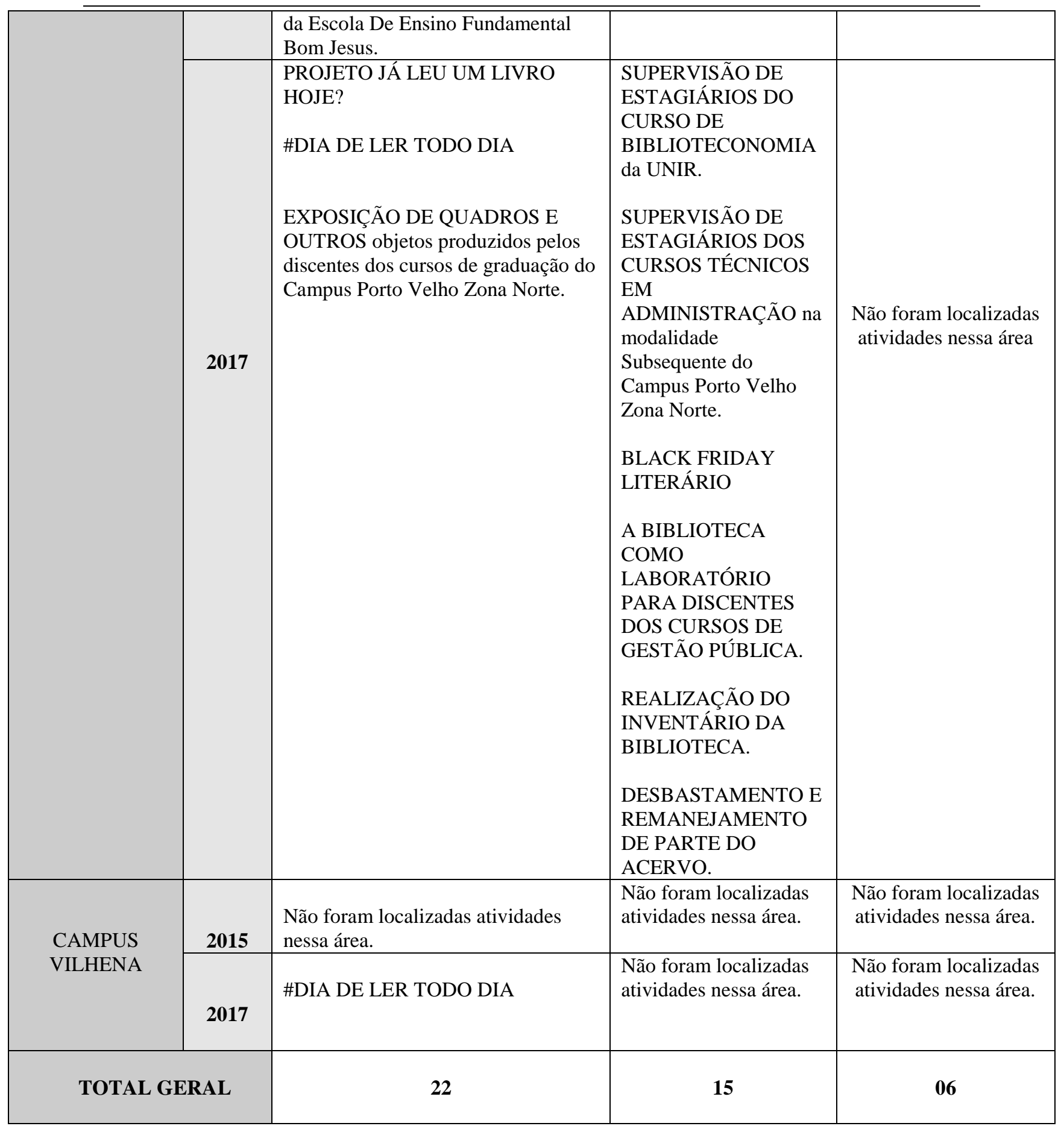

Fonte: Elaborado pelas autoras, com base no Relatório Geral de Bibliotecas do IFRO (2015 e 2017)

Lucas apud Fonseca (1996; 1992, p.14), afirma que a "formação dos Bibliotecários sempre esteve, entre a erudição e a técnica. A formação erudita tem sua tradição na École Nationale de Chartes, fundada em Paris, em 1921; Melvil Dewey, por sua vez, fundou na Universidade de Columbia, nos Estados Unidos, uma escola de orientação técnica". Por isso, muitas vezes a formação do bibliotecário na graduação no Brasil é voltada quase que exclusivamente para a área da técnica biblioteconômica e da gestão administrava.

A maioria dos profissionais bibliotecários brasileiros é contratada para trabalhar em bibliotecas públicas, escolares e universitárias. Essas unidades de informação necessitam que profissionais bibliotecários dominem a técnica biblioteconômica. Porém, entendemos que dentro da chamada Sociedade da Informação o 
bibliotecário ganhou uma nova função que é o papel de educador informacional, que deve ajuda a formar cidadãos competentes no uso da informação.

$\mathrm{Na}$ Sociedade da informação, existe uma grande parcela da população que têm acesso a milhares de informações, porém, há a necessidade de educar informacionalmente esta sociedade como destaca Albuquerque e Borges (2014, p.22) "desde os níveis básicos da escolarização, os alunos desenvolvam habilidades para identificar a relevância dos conteúdos veiculados pelos meios de comunicação e demais canais informacionais". Concordamos com a pesquisadora Kuhlthau (2002, p. 9-10), quando a mesma a destaca que:

Os saberes elaborados socialmente estão registrados em materiais diversos, que vão desde os tradicionais textos impressos, passando pelos recursos audiovisuais, até as informações virtualmente dispostas. [...] Para se preparar para as atuais complexas condições de trabalho o estudante tem que desenvolver a capacidade de aprender continuamente: precisa ter autonomia na sua relação com o conhecimento, isto é, deve conhecer suas próprias necessidades de informação e saber como obtê-la e utilizá-la para atender seus propósitos.

O trabalho de educar informacionalmente, dentro das escolas e universidades, deve ser feito em parceria com as chefias, bibliotecários, auxiliares de bibliotecas e professores. Todos estes profissionais devem entender que educar informacionalmente um aluno é incentiva-lo a ter um senso crítico da informação que recebe e que dispõe para a sociedade.

No levantamento das informações, que foram recolhidas com a aplicação de questionário, que foram enviados a 14 bibliotecárias do IFRO, que formavam a população geral do estudo, apenas 07 profissionais responderam. Com as respostas, percebemos que as bibliotecárias se esforçam para atender as demandas educativas $\mathrm{e}$ necessidades informacionais que surgem nos campi do IFRO.

No questionário colocamos nove questões, porém, destacamos aqui, as inquirições sobre o nível de formação profissional, no tocante a práticas educativas e pedagógicas voltadas para as bibliotecas. Na premiria inquirição verificamos a idade das servidoras que ficou entre 31 a 50 anos de idade.

Na segunda questão, questionamos sobre a formação acadêmica das profissionais. Seis bibliotecárias informaram que possuem especialização, uma profissional informou que possui apenas a graduação e outra destacou que possui mestrado. (Gráfico 1).

Gráfico -1 Nível de formação das bibliotecárias do IFRO.

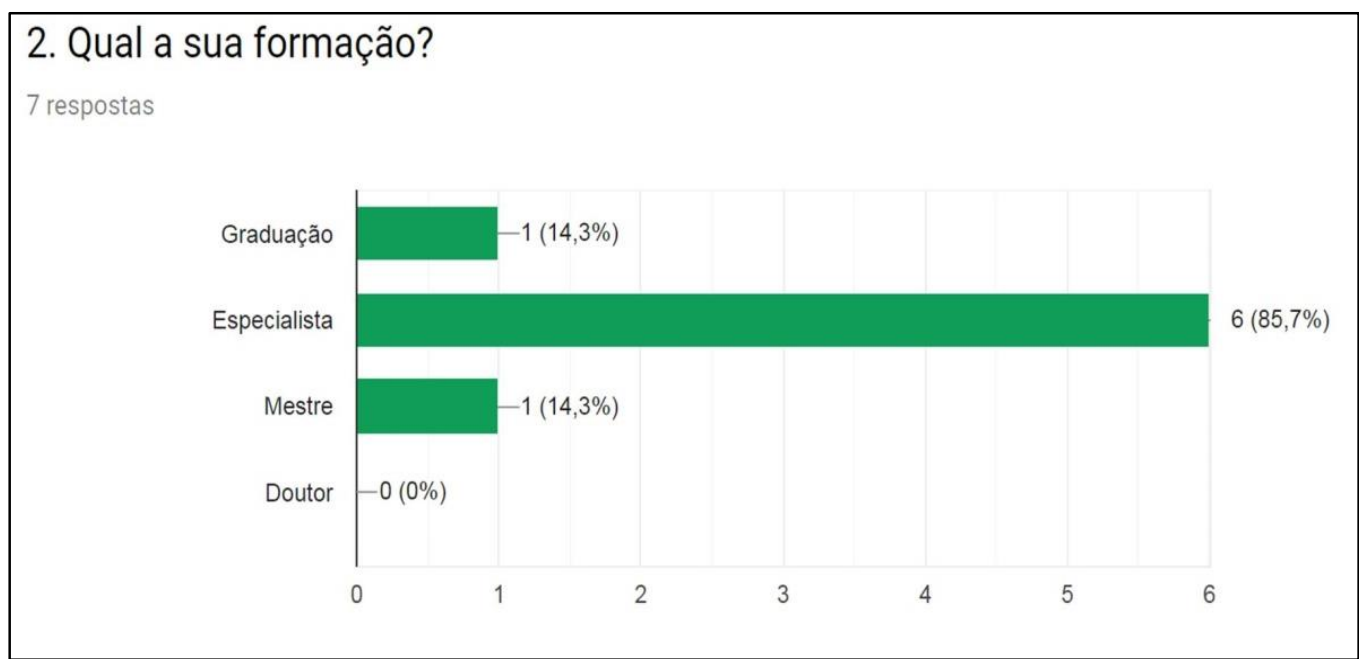

Fonte: Elaborados pelas autoras, 2018

$\mathrm{Na}$ terceira inquirição, buscamos verificar se as profissionais na graduação em Biblioteconomia haviam recebido, alguma orientação sobre competência informacional ou ações educativas em bibliotecas. 
Gráfico - 2 Formação das bibliotecárias do IFRO no tocante as práticas educativas ou de competência informacional na graduação.

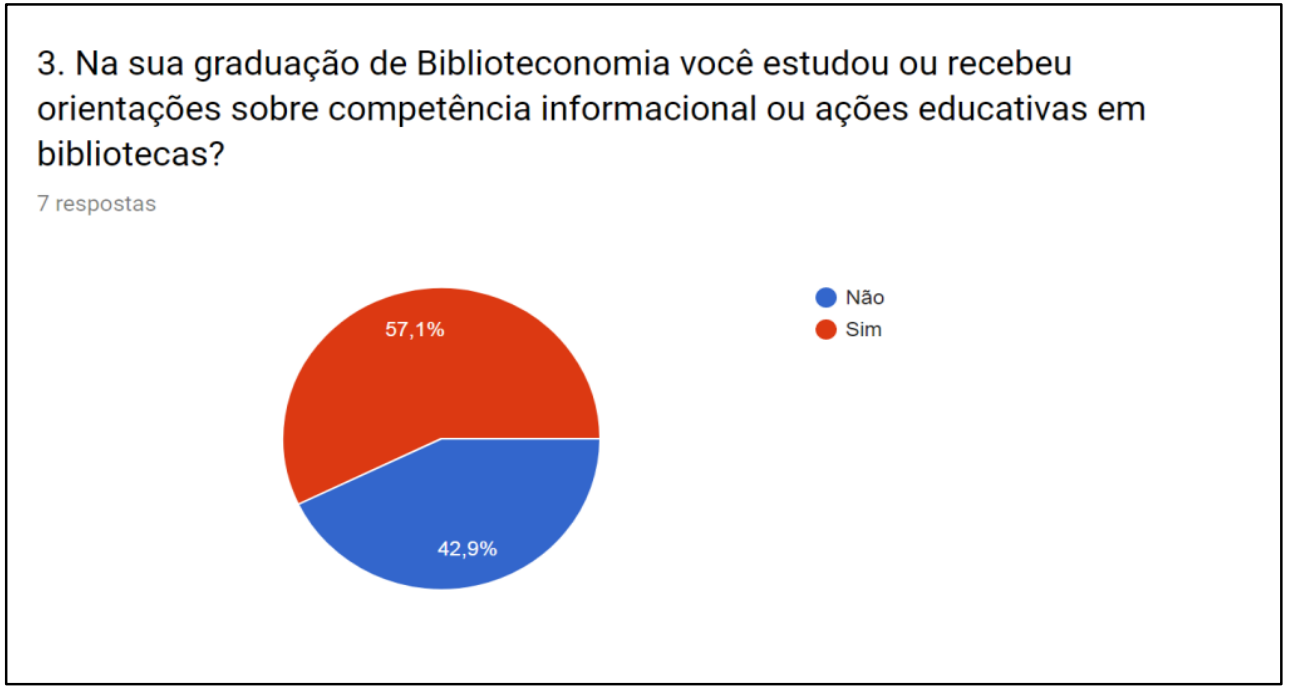

Fonte: Elaborados pelas autoras, 2018

$57,1 \%$ informou que sim haviam recebido, enquanto que $42,9 \%$ informaram que não. (Ver gráfico 2). Dando sequência a esta inquirição questionamos as profissionais que haviam respondido positivamente, como havia sido a experiência.

Algumas destacaram que a vivência "Foi maravilhosa! Aprendi muito nas diferentes unidades de informação que estagiei. Aulas práticas que tive e seminários que participei como ouvinte". Outra profissional destacou que a prática foi "Bastante motivadora. Foi por meio das disciplinas que fortaleci minhas ações para formação de leitores e incentivo à pesquisa na biblioteca escolar". De acordo com Castrillón, (2011), a "A biblioteconomia deve contribuir para encontrar soluções ao problema da desinformação, originado da manipulação que a mídia faz da informação", percebemos que as profissionais bibliotecárias do IFRO e da Rede Federal (EPCT) buscam ajudar a comunidade educativa em que estão inseridas, porém se faz necessário um planejamento formativo e um olhar especial para ajudar essas profissionais nos desenvolvimento de suas atividades, que têm um único objetivo ajudarem a melhorar o ensino tecnológico e científico oferecido pela Rede Federal EPCT.

Em vista dos pressupostos apresentando e após a realização de estudos com os usuários (professores e alunos) da Biblioteca Multinível do IFRO Campus Porto Velho Calama e com as bibliotecárias, elaboramos um Programa Educativo de Letramento Informacional, que é uma proposta de aplicação didática de incentivo ao letramento informacional no Instituto Federal de Educação, Ciência e Tecnologia de Rondônia-IFRO.

Ressaltamos que o programa pode ser utilizado por todas as bibliotecas multiníveis da Rede Federal (EPCT). Pois, o programa visa ajudar o educando a aprender e a utilizar à informação de forma correta e ética, e por fim, entender a importância da informação na sua formação escolar e acadêmica.

\section{CONSIDERAÇÕES FINAIS}

Quando nos propomos a entender o desafio educacional dos profissionais bibliotecários e bibliotecárias que atuam nas Bibliotecas Multiníveis da Rede Federal de Educação Profissional, Científica e Tecnológica (RFEPCT), procuramos abrir um espaço de discursão sobre a melhoria dos serviços educacionais ofertados pelas bibliotecas do IFRO e da Rede Federal (EPCT). Percebemos que as bibliotecárias já executam atividades educacionais. Porém, não de forma planejada.

Com as informações coletadas na pesquisa, a construção de um programa educativo de Letramento Informacional se enriqueceu e percebemos que há necessidade, para que seja apresentado as bibliotecárias, o conceito de Letramento Informacional, que visa capacitar alunos e professores na identificação, acesso, localização, obtenção e uso ético da informação. Além de tudo isso, o aluno educado informacionalmente, pode avaliar 
todo o processo informacional em prol de uma contínua aprendizagem. $\mathrm{O}$ letramento informacional possui componentes que são necessários para a sua real efetivação, esses componentes são: o processo investigativo, aprendizado ativo, aprendizado independente, pensamento crítico, o aprender a aprender e o aprendizado ao longo da vida. Todos esses componentes, são necessários para que leve o educando ao aprendizado, não apenas ao longo da vida, mas também que, o auxilie no pensar reflexivo com o uso correto da informação.
Portanto, as bibliotecas multiníveis são espaços privilegiados, pois possuem profissionais educadores: Bibliotecários e auxiliares de Bibliotecas, que em conjunto com professores e técnicos administrativos, podem realizar atividades planejadas de Letramento Informacional em suas comunidades de aprendizagem, contribuindo assim para a produção e melhoria dos conhecimentos científicos e tecnológicos produzidos pela Rede Federal (EPCT) no Brasil.

\title{
THE EDUCATIONAL CHALLENGE OF LIBRARIANS IN THE MULTILEVEL LIBRARIES OF THE FEDERAL NETWORK OF PROFESSIONAL, SCIENTIFIC AND TECHNOLOGICAL EDUCATION
}

\begin{abstract}
This work is part of a research developed at a master's level in Education, having as a locus of the study, the libraries of the Federal Institute of Education, Science and Technology of Rondônia (IFRO), belonging to the Federal Network of Professional, Scientific and Technological Education (RFEPCT ). The objective was to know and understand the practices and the educational projects, both developed by the professional librarians of IFRO. The method used was the inductive one, having as research type, action research. The instruments used were documentary analysis and the application of semi-structured questionnaires. As a result of the research, we have found that Federal Network Libraries (EPCT) is a new type of library, and should be called a Multilevel Library. We also observed that one of the greatest educational challenges for librarians is the planning and execution of educational informational projects, aimed at the Critical Information Competence of the student. Therefore, we map the activities and relate them to the creation of an Educational Information Literacy Program, which aims to improve and plan the educational activities and projects offered by the IFRO and Federal Network (EPCT) Libraries.
\end{abstract}

Keywords: Information Literacy. Librarians. Professional education.

\section{REFERÊNCIAS}

ALBUQUERQUE, Ana Cristina de; BORGES, Claudineia Aparecida Bertin. Pesquisa escolar: percurso de ação rumo ao Conhecimento. Informação@profissões, Londrina, v. 3, n. 1/2, p.21-41, 01 jan. 2014. Anual. Disponível em:

$<$ http://www.uel.br/revistas/uel/index.php/inf oprof/index>. Acesso em: 05 dez. 2018.

ALMEIDA, Jobson Louis Santos. A biblioteca como organização aprendente: o desenvolvimentismo de competências em informação no Instituto Federal de Educação, Ciência e Tecnologia da Paraíba. 2015. 122 f. Dissertação (Mestrado) - Curso de Biblioteconomia, Universidade Federal da Paraíba - UFPB, João Pessoa, 2015.

BUFREM, Leilah Santiago. Fundamentos sociais e políticos da biblioteconomia. Educ. rev., Curitiba , n. 4, p. 108-122, Dec. 1985. Available from <http://www.scielo.br/scielo.php?script=sci a rttext\&pid=S0104- 
$40601985000100008 \& \operatorname{lng}=\mathrm{en} \& \mathrm{nrm}=\mathrm{iso}>$. access on 06 Nov. 2018. http://dx.doi.org/10.1590/0104-4060.050.

BRASIL. Constituição da República Federativa do Brasil. Brasília: Senado Federal, 1988. Acesso em 18 de junho de 2015.

CAMPELLO, Bernadete Santos. Letramento Informacional no Brasil: práticas educativas de bibliotecários em escolas de Ensino Básico. Tese (doutorado) - Universidade Federal de Minas Gerais, Escola de Ciência da Informação, 2009.

CASTRILLÓN, S. O direito de ler e de escrever. Tradução de Marcos Bagno. São Paulo: Pulo do Gato, 2011.

DUDZIAK, E. A. Information Literacy: princípios, filosofia e prática. Ci. Inf., Brasília, v. 32, n. 1, jan./abr. 2003.

FREIRE, Paulo. Pedagogia da autonomia: saberes necessários à prática educativa. São Paulo: Paz e Terra, 1996.

GASQUE, Kelley Cristine Gonçalves Dias. Letramento Informacional: pesquisa, reflexão e aprendizagem. Brasília: Faculdade de Ciência da Informação / Universidade de Brasília, 2012. 175 p.

KUHLTHAU, Carol Collier. Como usar a biblioteca na escola: um programa de atividades para ensino fundamental.

(Traduzido e adaptado por Bernadete Santos Campello et al.). Belo Horizonte: Autêntica, 2002.

HUBNER, Marcos Leandro Freitas; KUHN, Ana Carolina Araújo. Bibliotecas universitárias como espaços de aprendizagem. Biblos: Revista do Instituto de Ciências Humanas e da Informação, Rio Grande do Sul, v. 31, n. 1, p.51-72, 01 jan. 2017.

Semestral. Disponível em: <file:///C:/Users/1921139/Downloads/650920252-1-PB.pdf >. Acesso em: 16 nov. 2018.

LEAL, Bruno. Biblioteconomia e

bibliotecas: muito além do tecnicismo. 2017. Disponível em:

$<$ https://www.cafehistoria.com.br/bibliotecon omia-e-biblioteca/>. Acesso em: $01 \mathrm{dez}$. 2018.

LUCAS, Clarinda Rodrigues. Indexação: gestos de leitura do bibliotecário. 1996. $100 \mathrm{f}$. Tese (Doutorado) - Curso de

Biblioteconomia, Universidade de Campinas Unicamp, Campinas, 1996. Disponível em: <http://repositorio.unicamp.br/bitstream/REP OSIP/270726/1/Lucas_ClarindaRodrigues_D. pdf>. Acesso em: 08 set. 2018.

MESSIAS, Lucilene Cordeiro da Silva. Informação: um estudo exploratório do conceito em periódicos científicos brasileiros da área de Ciência da Informação Marília. 2005. 206 f. Dissertação (Mestrado em Ciência da Informação) - Programa de Pós Graduação em Ciência da Informação, Faculdade de Filosofia e Ciências, Universidade Estadual Paulista, Marília, 2005. Cap. 14.

ONU. Declaração Universal dos Direitos Humanos. Brasília: UNESCO, 1948. 6p.

PIMENTA, Selma Garrido. Pesquisa-ação crítico-colaborativa: construindo seu significado a partir de experiências com a formação docente. Educação e Pesquisa, São Paulo, v. 31, n. 3, p.521-539, 16 jun. 2018. Semestral.

PORTO VELHO (RO). Resolução ${ }^{\circ}$ 21/2015, CONSUP/IFRO de 06 de junho de 2015. Dispõe sobre o Regulamento de Funcionamento de Bibliotecas do Instituto Federal de Educação, Ciência e Tecnologia de Rondônia - IFRO. Porto Velho, 2015.

PORTO VELHO (RO). Resolução ${ }^{\circ}$ 22/2015, CONSUP/IFRO de 06 de julho de 2015. Dispõe sobre a Política de Desenvolvimento de Coleções do Instituto Federal de Educação, Ciência e Tecnologia de Rondônia - IFRO. Porto Velho, 2015.

PORTO VELHO (RO). Resolução ${ }^{\circ}$ 65/2015, CONSUP/IFRO, de 29 de dezembro de 2015. Dispõe sobre o Regimento Geral do Instituto Federal de Educação, Ciência e Tecnologia de Rondônia - IFRO. Porto Velho, 2015.

VEIGA, Miriã Santana. Programa educativo de letramento informacional: uma proposta 
de aplicação ao Instituto Federal de Educação, Ciência e Tecnologia de Rondônia - IFRO. Porto Velho - RO: Ifro, 2017. 54 p.

WERTHEIN, Jorge. A sociedade da informação e seus desafios. 2000. Ciência da Informação, Brasília. Disponível em:

$<$ http://www.scielo.br/pdf/ci/v29n2/a09v29n2 .pdf>. Acesso em: 10 ago. 2018. 